\title{
New Virtual Environment for Active Learning on Parameter Adjustment of Plastic Injection Molding
}

\author{
Marquez. J.J. , Rodriguez. M. , Martinez. M.L. and Perez. J.M.
}

Dept. Of Mechanical \& Manufacturing Engineering. E.T.S.I. Industriales. Universidad Politécnica de Madrid. C. José Gutierrez Abascal, 2, 28006 Madrid, Spain

imarquez@etsii.upm.es, mrvillagra@etsii.upm.es, muneta@etsii.upm.es, iperez@etsii.upm.es

Keywords: Injection Molding, Simulator, Polymer Processing, Virtual Reality.

\begin{abstract}
This paper describes some aspects of new software development and its academic application. This program is an alternative to enhance and to improve the available resources for students to acquire practical knowledge in plastic injection molding parameterization. A virtual injection molding environment has been developed, which allows preliminary machine capacity determination, number of cavities analysis, injection cycle parameter definition, and defects analysis and representation. The environment allows the student to carry out an iteration process in order to optimize the injection molding process parameters. All decision making is based on an Expert System which response is similar to a skilled machine operator.
\end{abstract}

\section{Nomenclature}

C.- Total cost of produced lot.

$\mathrm{C}_{\mathrm{hm}}$. - Hourly cost of injection molding machine.

$\mathrm{C}_{\mathrm{ho}}$ - Hourly cost of personal.

$t_{\text {cycle-- Injection cycle time. }}$

Lot.- Lot size.

$\mathrm{C}_{\text {mold. }}$ - Mold cost.

$\mathrm{C}_{\mathrm{p}}$ - Plasticizing rate on injection molding machine.

$\mathrm{T}_{\mathrm{p}}$ - - Plasticizing time.

$\mathrm{W}_{\text {part }}$ - Injected part weight.

$W_{\text {sprue/runners. }}$ Injected sprue and runners weight.

$\mathrm{C}_{\mathrm{i}}$ - Injection rate on injection molding machine.

$\mathrm{V}_{\text {part }}$ - Part volume.

$\mathrm{V}_{\text {spruefrunners. }}$ - Sprue and runners volume.

$\mathrm{F}_{\text {clamp.- }}$ Clamping force on injection molding Machine.

Pclamp.- Clamping pressure on injection molding Machine.

$S_{\text {proy/part. }}$ - Part projected surface on demolding direction.

$\mathrm{S}_{\text {proy/sprue/tunners. }}$ - Sprue and runners projected surface on demolding direction.

\section{Introduction}

The employment of simulators is nowadays increasing in many applications. Training centers for airplane pilots, military devices or special vehicles were the initial developments within this field. Simulators have become more popular with the expanding capabilities of personal computers and consequent low cost and powerfulness of graphics hardware and software. Directly related with manufacturing processes, wide experiences have been carried out as Simpson [1], where students control all factors of productive process. Other similar approaches were carried out on Washington University [2], Shah [3] describes a realistic simulation on collaborative robust design of a product within an academic year. On Syracuse University [4] students can attend a course on serial fabrication to develop a specific product. Simpson [5] proposes to compare manual to serial 
fabrication on paper airplanes. Related with manufacturing process simulators based in expert systems, it is remarkable the work presented by Liu [6], where a modular system is developed for machine tool simulation. In other works like Lee [7], which is more specifically oriented to ultraprecision machining, two virtual solid machine models are presented. Virtual environments for control education are presented by Fernandez [8] developed in MATLAB GUI to be used in practical sessions and by Peek [9] with a DC-Motor simulator developed in NI LabVIEW.

Recently have appeared research approaches to virtual injection molding, Ma [10] develops a new virtual reality environment with the aim to reduce development time in the early mold design stage. Another work, Shen [11], presents a new method for combination of artificial neural network and genetic algorithm employed for process optimization. Optimal tuning of injection molding process has also been treated on previous works as Ivester [12] that employs a virtual environment provided by an input-output model to search, in an iterative way, the optimal input parameters. Other approach is a knowledge-based strategy, Yang [13], where an on-line estimation of the process window during tuning is provided. Capital influence of specific parameters in microinjection molding has also been recently modeled, $\mathrm{Su}[14]$.

Related with training of technical staff in plastic transformation processes, usually is encountered a natural difficulty to transmit know-how strongly based on skilled operators experience, which drives to an inefficient and time consuming formation programs. The present work is oriented to the development of an optimized software application to be used in injection molding process parametrization. There are some existing software applications that approach partially or collaterally this background problem. Program PICATß [15] allows to simulate and to modify the injection parameters of a part to study its possible defects. The program deals with four templates of part, of very simple and not realistic geometry. PICAT is basically machine operator training software and therefore oriented to complete the formation of partially trained personnel, for this reason, is not recommendable to new students within this field. On the other hand, PICAT discards problems of principal interest for a plastic transformation company such as the machine size to employ and the recommended number of cavities in the mold, and also neglects aspects related to the mold design, such as runners type, thermal balance, mold size, etc.

Other type of existing software applications are based in numerical simulation, generally oriented to improve mold design tasks, such as Moldflowß [16]. These programs have in common their mathematical modelization of the plastic flow during the transformation process and, complementary allow analyzing warpage and shrinkage defects. Nevertheless they are difficult to learn, and mainly it is remarkable the difficulty that involves the correct interpretation of the results that they provide, considering that a critical and specialized analysis is required. The conclusion is that only highly trained personnel can get confidence results of their use, and therefore are not suitable for new students.

\section{System Basis}

The basic problems in the injection process can be solved sequentially as follows:

1) Technical-economical problems derived from the preliminary definition of the mold.

2) Derived problems from machine selection among available machines.

3) Parameterization problems in injection cycle.

The final customer company (automotive, aeronautical, etc...) defines the geometry, material and lot size of the parts to inject. With these data, the plastic transformation company elaborates a production plan to obtain the maximum required geometrical and visual quality at lower cost possible, within its available resources (human and machinery with their respective operative costs). Early decisions are technical-economical, as the number of cavities in the mold, mold type, runners type, etc. (economic feasibility). Machine selection is the next step, injection rate, plasticizing rate, 
clamping force (technical feasibility). Finally the cycle parameterization is carried out adjusting, temperatures, times, pressures and velocities in the injection molding machine (part quality).

This procedure of decision making is difficult to transmit to the student, moreover, considering that within this sector; the different tasks are not carried out by a unique company. The raised methodology and the program developed, presented in this work, try to be a support for new students in injection process of thermoplastics and can solve these problems in a reasoned, effective and ordered way.

The defined methodology for decision making can be established in the following manner:

1.First estimation of number of cavities of the mold.

2.Technical limits on number of cavities attending on: machine plasticizing rate, machine injection rate, and machine clamping force.

3.Machine selection among available.

4.Cycle parameters definition.

5.Quality estimation on injected parts.

6.Cycle time optimization.

7.Number of cavities optimization.

These tasks are usually carried out by a skilled machine operator with years of experience that will provide, on an iterative procedure, optimization of cycle time and number of cavities. In the developed system, the operator knowledge will be replaced by an Expert System to obtain similar results.

First estimation of number of cavities can be done applying the following expression:

$$
C=\left(C_{t m}+C_{\text {tho }}\right) \cdot t_{c y c t e} \frac{L o t}{n^{\circ} c a v}+C_{m o l d}
$$

Eq. 1 represents the total cost of a part lot, without considering the material cost, and allows obtaining an initial recommendation for the most economical number of cavities, employing estimations for hourly cost on machine and operator, cycle time, lot size, and mold cost. Usually the regular behavior in lot sizes of typical consumer plastic parts is as represented on Fig. 1, where a minimum can be observed at determined mold number of cavities.

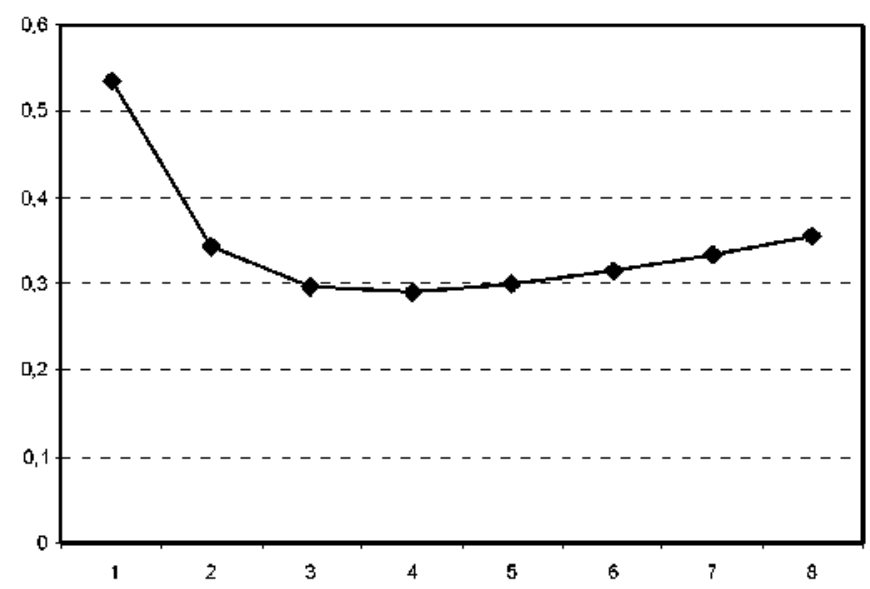

Figure 1.- Cost per unit versus number of cavities of the mold.

This economical number allows establishing a comparison criterion, with injection machinery specifications by means of the following equations: 


$$
\begin{aligned}
& N^{\mathrm{o}} \mathrm{cav}=\frac{C_{p} \cdot T_{p}-W_{\text {sprne/ rumners }}}{W_{\text {part }}} ; \\
& N^{0} c a v=\frac{C_{i}-V_{\text {sprue } / \text { rmmers }}}{V_{\text {part }}} \\
& N^{\circ} \mathrm{cov}=\frac{\frac{F_{\text {clamp }}}{P_{\text {clatup }}}-S_{\text {proy/sprue i runners }}}{S_{\text {proy/part }}} ;
\end{aligned}
$$

These equations are expressions of the maximum theoretical numbers concerning to injection machine specification attending to: plasticizing rate (Eq.2), injection rate (Eq.3), and clamping force (Eq.4). The most suitable machine will be selected to accomplish the economical number but under the technical limits.

The next step is to define the more suitable cycle parameters to get the objective quality on injected parts. Parameters on Tab.1, were selected as representative to define the injection cycle.

\begin{tabular}{|c|l|}
\hline T1 & Plasticizing temperature 1 \\
\hline T2 & Plasticizing temperature 2 \\
\hline T3 & Plasticizing temperature 3 \\
\hline T4 & Injection chamber temperature \\
\hline T5 & Nozzle temperature \\
\hline t1 & Injection time \\
\hline t2 & Hold pressure time \\
\hline t3 & Opening time \\
\hline t4 & Ejection time \\
\hline t5 & Closing time \\
\hline Pi & Injection pressure \\
\hline Vi & Injection velocity \\
\hline Pp & Part program \\
\hline
\end{tabular}

Table 1.- Injection cycle parameters

These parameters have been selected, for being more useable in the most of commercially available Injection Molding Machine configuration menus. To accomplish an estimation of injected parts quality, an Expert System has been developed. This system is empirically based on actual injection processes and Moldflow simulations, and allows predicting defect occurrences.

A representative set of defects has been selected, among all possible described in related bibliography [17], [18], [19], only those directly dependant on cycle parameters adjusted on the molding machine has been considered, discarding those derived from different causes, as for example those derived from incorrect part design (sinks marks, welding lines,...) or those derived from incorrect mold design (air occlusions, injection marks,...). On Tab. 2, defects considered as representative and directly related with injection molding cycle adjustable parameters are shown, also they have been ordered in importance of occurrence. 


\begin{tabular}{|l|l|}
\hline 1 & Temperature out of range \\
\hline 2 & Incomplete filling \\
\hline 3 & Exfoliation \\
\hline 4 & Warpage \\
\hline 5 & Ejectors marks \\
\hline 6 & Burning marks \\
\hline 7 & Discoloring \\
\hline
\end{tabular}

Table 2.- Defect hierarchy

On the other hand, expert system decision criteria have been established to correlate cycle parameters versus defect appearance, in order to predict defect intensity from 1 (neglectfully) to 4 (severe). Tab. 3, shows defects and intensity inferred by the expert system as response to determined cycle parameters or combinations, Temperature out of range (defect \#1) implies no possibility to inject, and " 0 " means that no defect is predicted.

The described methodology allows estimating, in an iterative and realistic manner, cycle parameters for injection molding process to assure injected parts free of defects, as well as cycle time estimation which allows economical optimization. To apply the developed methodology, to be employed by students, a new software application has been programmed.

\begin{tabular}{|c|c|c|c|c|c|}
\hline & \multicolumn{5}{|c|}{ Inferred Defects } \\
\hline Controlled Parameter & & \begin{tabular}{|l|l|l}
3 & 4 \\
\end{tabular} & & & \\
\hline $\mathrm{T} 1$ to $\mathrm{T} 5 \uparrow$ & 0 & \begin{tabular}{l|l}
2 & 0 \\
\end{tabular} & 0 & & 2 \\
\hline T5 $\downarrow$ & 1 & \begin{tabular}{l|l}
0 & 0 \\
0
\end{tabular} & 0 & 0 & 0 \\
\hline $\mathrm{t} 1 \downarrow$ & 2 & \begin{tabular}{l|l}
2 & 1 \\
\end{tabular} & 0 & 0 & 0 \\
\hline tl $\downarrow \downarrow$ & 4 & \begin{tabular}{l|l|l}
4 & 4 \\
\end{tabular} & 0 & 0 & 0 \\
\hline $\mathrm{t} 2 \downarrow$ & 0 & \begin{tabular}{l|l}
1 & 1 \\
\end{tabular} & 1 & 0 & 0 \\
\hline $\mathrm{t} 2 \downarrow \downarrow$ & 0 & \begin{tabular}{l|l|l}
4 & 4 \\
\end{tabular} & 4 & 0 & 0 \\
\hline $\mathrm{t} 2 \uparrow \uparrow$ & 0 & \begin{tabular}{l|l}
0 & 0 \\
\end{tabular} & 0 & 0 & 1 \\
\hline pi $\downarrow$ & $0 \mid$ & $1 \mid 1$ & 0 & 0 & 0 \\
\hline pi $\downarrow \downarrow$ & 3 & \begin{tabular}{l|l}
4 & 4 \\
\end{tabular} & 0 & 0 & 0 \\
\hline $\mathrm{pi} \uparrow \uparrow$ & 0 & \begin{tabular}{l|l}
0 & 0 \\
\end{tabular} & 0 & 0 & 0 \\
\hline vi $\downarrow$ & 2 & \begin{tabular}{c|c}
0 & 0 \\
\end{tabular} & 0 & 0 & 0 \\
\hline $\mathrm{vi} \uparrow$ & 0 & $1 \mid 1$ & 0 & 0 & 0 \\
\hline $\mathrm{T} 5 \downarrow \mathrm{t} 1 \downarrow$ & 4 & \begin{tabular}{l|l}
4 & 4 \\
\end{tabular} & 0 & 0 & 0 \\
\hline $\mathrm{t} 1 \downarrow \mathrm{t} 2 \downarrow \mathrm{pi} \downarrow$ & 4 & \begin{tabular}{l|l|}
4 & 4 \\
\end{tabular} & 1 & 0 & 0 \\
\hline $\mathrm{T} 2 \uparrow \mathrm{pi} \downarrow$ & 0 & \begin{tabular}{l|l}
0 & 0 \\
\end{tabular} & 0 & 1 & 0 \\
\hline $\mathrm{t} 1 \uparrow \mathrm{t} 2 \downarrow$ pi $\downarrow$ vi $\uparrow$ & 2 & \begin{tabular}{l|l}
4 & 4 \\
\end{tabular} & 1 & 0 & 0 \\
\hline $\mathrm{T} 1$ to $\mathrm{T} 5 \uparrow \mathrm{t} 2 \uparrow$ & $0 \mid$ & & & & 4 \\
\hline
\end{tabular}

Table 3.- Defects inferred for certain parameters or combinations

\section{Developed Program}

The program management is guided from a main panel which can be observed in Fig. 2. 


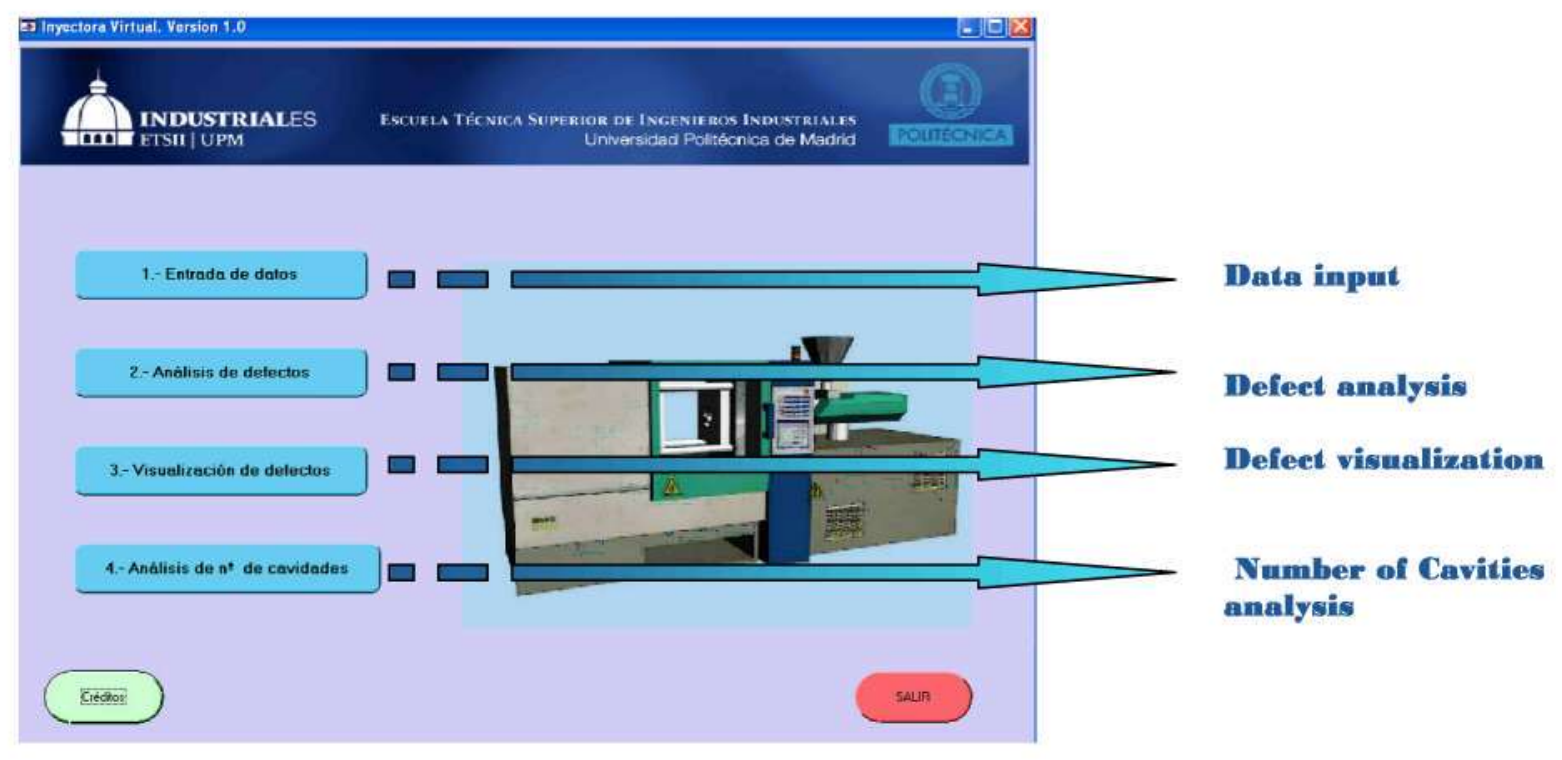

Figure 2.- Main application panel

From this window the student has access to the different functionalities of the program:

1) Virtual Simulator for injection molding process data input.

2) Expert system to estimate injected parts quality.

3) Defects visualization.

4) Technical-Economical analysis of number of cavities.

In Fig. 3, one of the Virtual Simulator windows can be observed. A determined amount of parts were selected as representative of sizes and materials used in consumer products. The student can select starting from the part geometry, material, machine size, and cycle parameters to simulate the injection molding of this part.

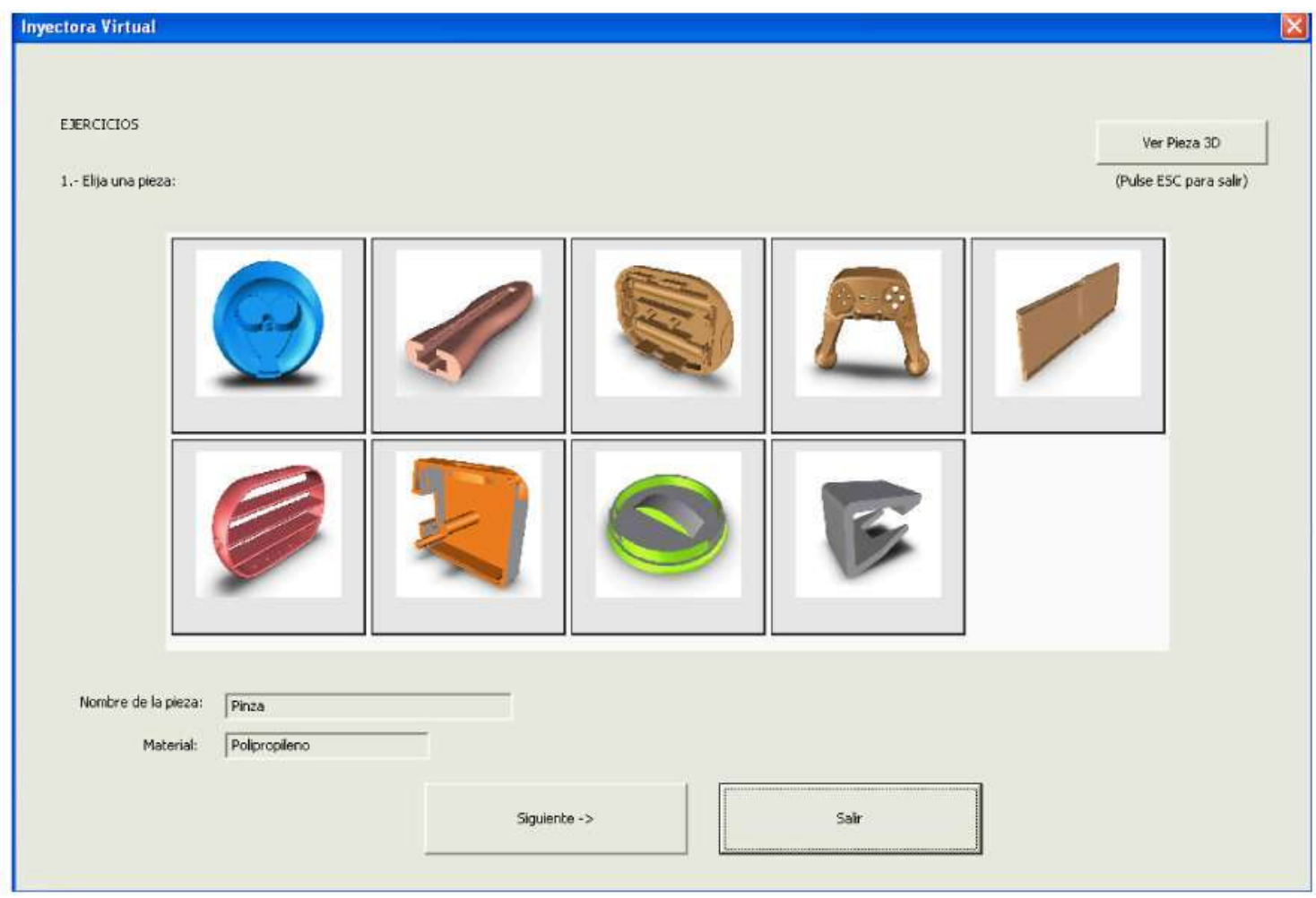

Figure 3.- Part selecting window and a part example 
The program has been developed on a visual programming environment which allows incorporating three dimensional interactive representations, so a virtual machine quite similar to those commercially available can be shown to the student. This virtual model has been developed employing an OSG (OpenSceneGraph) based graphical motor, which allows the student selecting different points of view of the scene, maintaining the operability of the panel push-buttons. Once the part, material, and machine size have been selected, the student is driven into a virtual injection machine simulator (Fig. 4), which shows a three dimensional visualization, where the student can interact reproducing the typical machine movements and introducing injection cycle parameters for further analysis. Data interchangeability with virtual environment is based in CORBA (Common Object Request Broker Architecture) standard of communications.

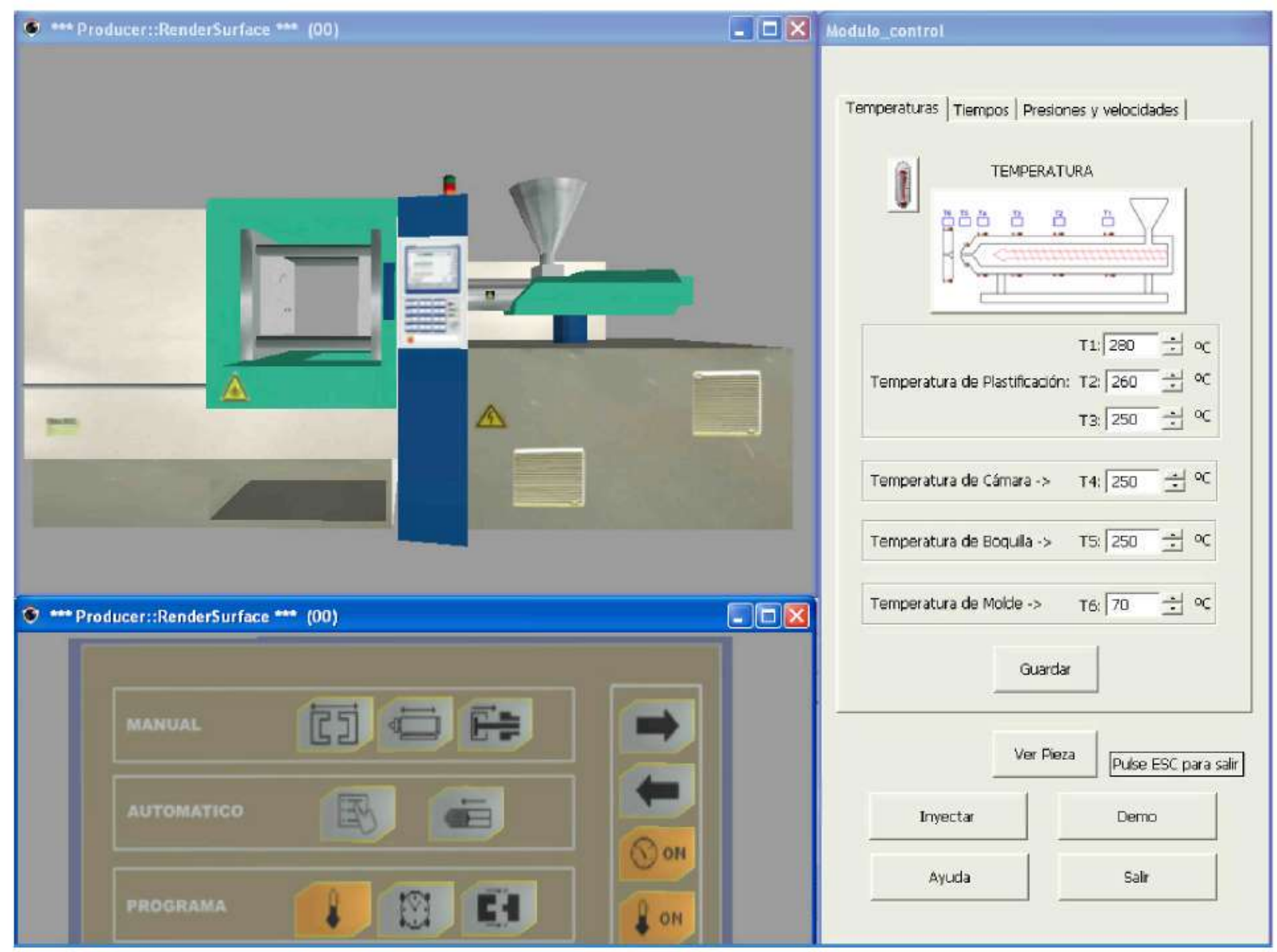

Figure 4.- Virtual simulator environment

After the cycle parameters have been chosen, a defect analysis can be carried out, which generates a visual output to observe the defects occurrence (Fig. 5). 


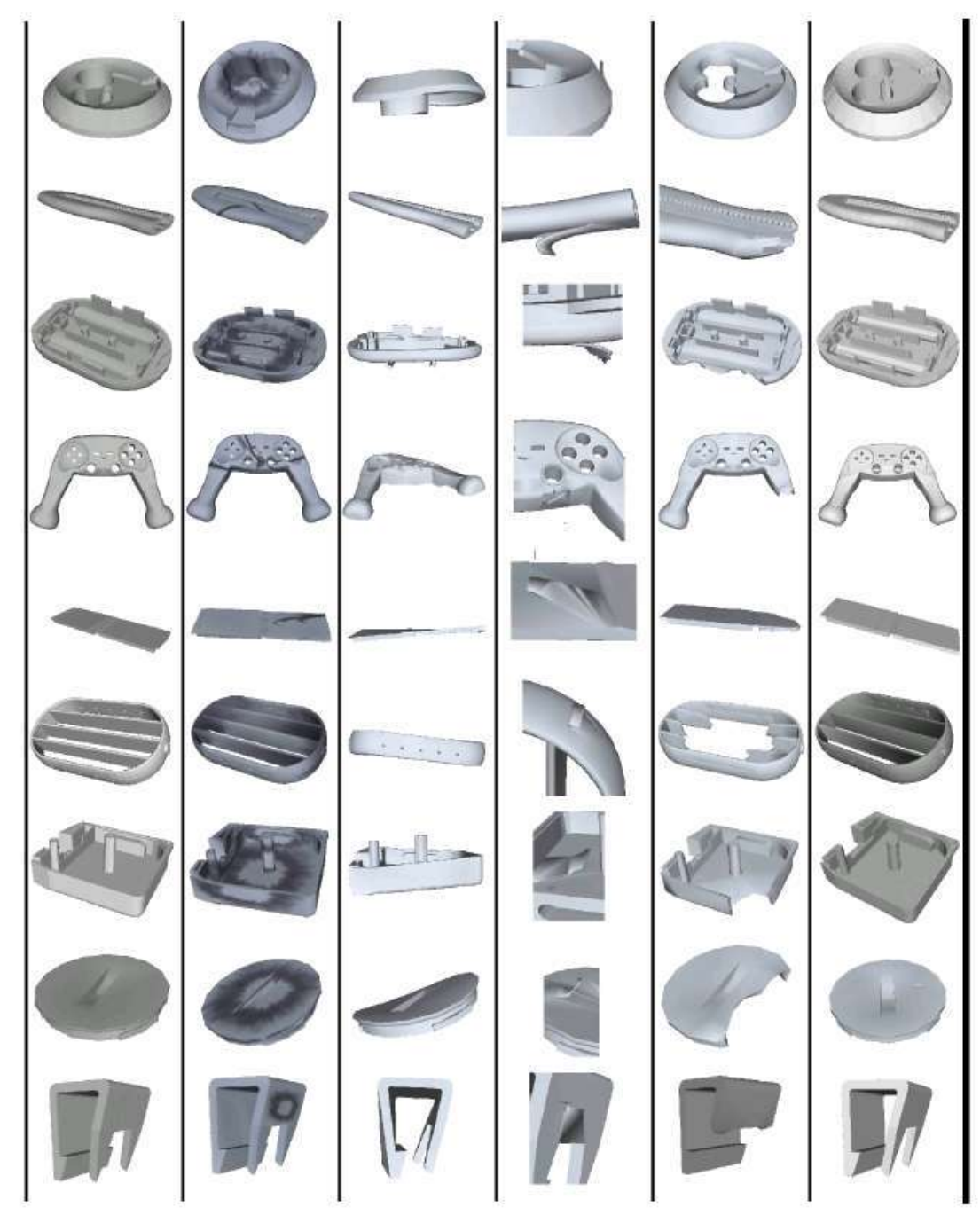

Figure 5.- Examples of visualization of defects occurrence, Burning marks, Warpage, Exfoliation, Short Shots, Ejectors marks

Finally Fig. 6, shows the panel employed to carry out the technical-economical analysis recommended for the mold. This is a very useful panel to estimate the actual mold dimensions, more suitable from the economical point of view, as well as the optimal machine size to carry out the transformation process. 


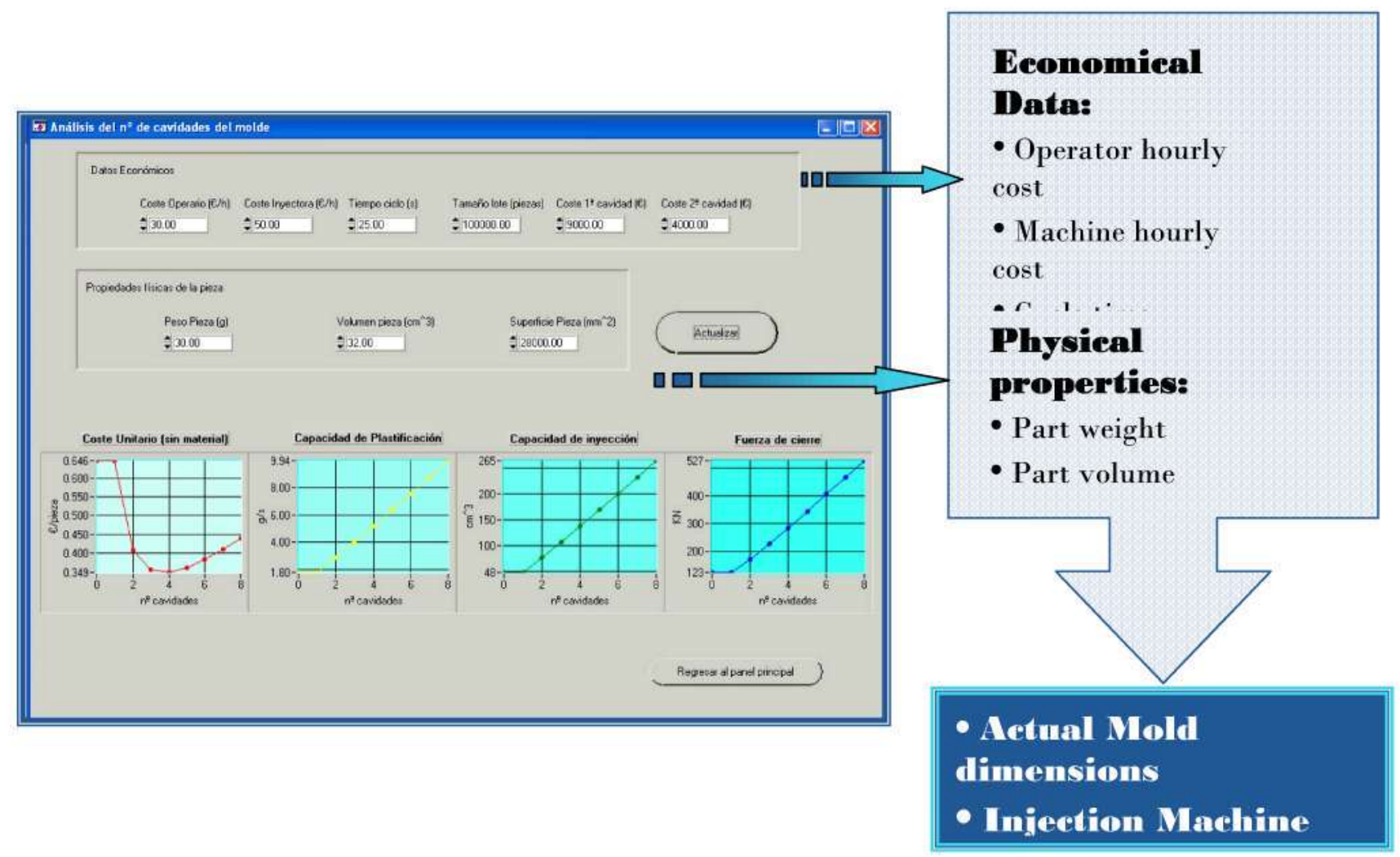

Figure 6.- Technical-economical analysis panel

\section{Academic Results}

The course "Design and Manufacturing with Plastics" is imparted on the 10th semester of the Mechanical \& Manufacturing Engineer degrees, on the Universidad Politecnica of Madrid. The basic time distribution is:

- $96 \mathrm{hr}$. divided in theoretical and practical lectures

- $84 \mathrm{hr}$. in personal student work

A total of $180 \mathrm{hr}$. equivalent to 6 ECTS are related. The course topics are shown in Tab. 4.

\begin{tabular}{|l|}
\hline Part 1: Polymeric Materials and fabrication processes \\
\hline Introduction to polymeric materials \\
\hline Polymer fabrication processes \\
\hline Fabricability analysis on polymeric parts \\
\hline Defects on injected polymeric parts \\
\hline Injection molding process parameterization \\
\hline Injection mold design \\
\hline Part 2: Design of parts in Polymeric materials \\
\hline Design process and material selection \\
\hline Flexural, screwed, snap fitting \& press fitting Joints \\
\hline Design \& calculus considerations in plastic gears \\
\hline Tensional analysis in polymeric parts \\
\hline Real cases analysis \\
\hline CAD Modeling \\
\hline Rapid prototyping \\
\hline
\end{tabular}

Table 4.- Compact course program 
A testing release of the developed program has been used with actual students during the second semester of 2006-2007 academic year, in the course of the practical lectures related with the themes "Defects on injected polymeric parts" and "Injection molding process parameterization". The results obtained are very promising, taking into account that only a control group of fifteen students has been evaluated to test the academic impact of the program usefulness. From data observed in Fig. 7 , it can be deduced that a significant improvement of marks in a control test, can be derived from the program use, which reaches a mean value of increment superior to $33 \%$.

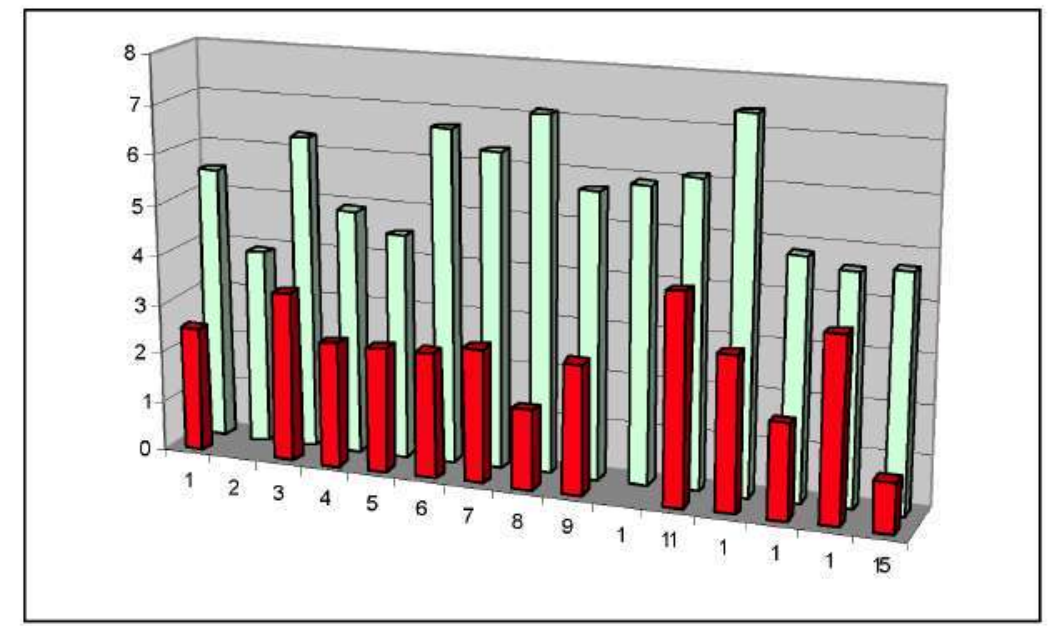

Figure 7.- Academic results evolution in control group of students

From a detailed ANOVA analysis (Fig. 8) attending to group factor (group of 24 students without virtual simulator employment, versus 15 students control group), it can be concluded that this factor has a statistically significant effect on marks at the $95 \%$ confidence level.

\section{Means and 95,0 Percent LSD Intervals}

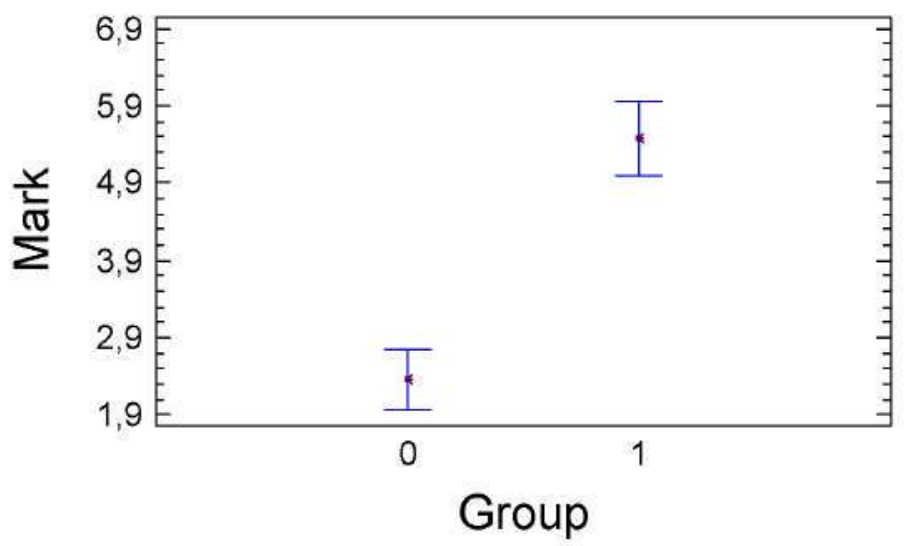

Figure 8.- ANOVA analysis

On the other hand, an important grade of acceptance has been detected among students for this new learning experience accordingly to results obtained in the opinion survey Tab. 5, where this new learning activity has been very well evaluated, considering it very useful as a complement for the course. 


\begin{tabular}{|l|c|c|c|}
\hline & Yes & No & Partially \\
\hline Clear objectives & 15 & 0 & 0 \\
\hline Good program structure & 10 & 0 & 5 \\
\hline Professor advisory & 12 & 0 & 3 \\
\hline Longer activity duration & 2 & 11 & 2 \\
\hline Good global evaluation & 14 & 0 & 1 \\
\hline
\end{tabular}

Table 5.- Virtual Simulator opinion survey

\section{Conclusions}

In the present work a new methodology for new student training, in the field of plastic injection molding has been established. This new approach allows carrying out the technical-economical analysis of the process as well as to define the cycle parameters to get the maximum quality in injected parts. The application software developed has demonstrated its efficiency, and students have reached better results after its use. The expert system, that supports the decision criteria for the program represents an important basis to develop other optimization approaches for injection molding, and for other polymer transformation processes.

\section{Acknowledges}

This work has been completely funded by the Vicerrectorado de Ordenacion Academica $y$ Planificacion Estrategica of the Universidad Politecnica de Madrid (UPM) within the 2006 Innovation Program, project IE06 0525-049.

\section{References}

[1] Simpson, W.; Medeiros, J. et. al.; "IME.Inc. A new course for integrating design, manufacturing and production into the engineering curriculum". Int. J. Engineering Education. Vol. 20, Num. 5, pp.764-766, 2004.

[2] Lamancusa, J.S.; Jorgesen, J.E; Zayas-Castro, J.L.; "The learning factory: a new approach to integrating design and manufacturing into the engineering curriculum". J. Engineering Education. Vol. 88, Num. 6, pp. 103-102, 1997.

[3] Shah, J.J.; Sadowky, J.S.; Macia N.F. et. al,; "The virtual corporation: simulating real World collaborative design in a university setting". ASME Design and Methology - DTM'95 Boston MA. Vol. 2, pp. 507-515, 1995.

[4] Carranti, F.J.; "A manufacturing enterprise for undergraduates". Successes in M.E. Design Education, ASME International Congress and Exposition, Nashville, TN. pp. 7-12, November 1999.

[5] Simpson, T.W.; "Experiences with a hands-on activity to contrast craft production and mass production in the classroom". International Journal of Engineering Education. Vol. 19, Num. 2, 2003.

[6] Liu, J.; Landers, R.G.; "Integrated Modular Machine Tool Simulation for Education in Manufacturing Automation". Int. J. Engineering Education. Vol. 20, No. 4, pp. 594-611, 2004.

[7] Lee, W. B.; Li, J. G.; Cheung, C. F.; "Development of a Virtual Training Workshop in Ultraprecision Machining". Int. J. Engineering Ed. Vol. 18, No. 5, pp. 584-596, 2002 
[8] Fernández, C.; Vicente M. A.; Jiménez L.M.; "Virtual Laboratories for Control Education: a Combined Methodology". Int. J. Engineering Education. Vol. 21, No. 6, pp. 1059-1067, 2005.

[9] Peek, C. S.; Crisalle, O. D.; et al; "The Virtual Control Laboratory Paradigm: Architectural Design Requirements and Realization through a DC-Motor Example". Int. J. Engineering Education. Vol. 21, No. 6, pp. 1134-1147, 2005.

[10]Ma B.; Guo ZY.; Zhou HM.; Li DQ; "Virtual plastic injection molding based on virtual reality technique". International Journal of Advanced Manufacturing Technology 31 (11-12): 10921100 Feb 2007.

[11] Shen C.; Wang L.; Li Q.; "Optimization of injection molding process parameters using combination of artificial neural network and genetic algorithm method". Journal of Materials Processing Technology 183 (2007) 412-418.

[12] Ivester R.; Danai K; "Automatic tuning and regulation of injection molding by the Virtual Search Method". Journal of Manufacturing Science and Engineering-Transactions of the ASME 120 (2): 323-329 May 1998.

[13] Yang, D.; Danai, K.; Kazmer D.; "A Knowledge-Based Tuning Method for Injection Molding Machines". Transactions of the ASME Vol. 123, 682-691 Nov 2001.

[14] Su, Y.; Shah, J.; Lin, L.; "Implementation and analysis of polymeric microestructure replication by Micro Injection Moulding”. Journal of Micromechanics and Microengineering. Vol. 14, pp. 415-422, 2004.

[15]Polymer Training Limited PTL (PICAT). Halesfield 7 Telford. Shropshire TF7 4NA. United Kingdom. http://www.ptlonline.org.uk/home.htm

[16]Moldflow Corporation. 492 Old Connecticut Path, Suite 401. Framingham, MA 01701 USA. http://www.moldflow.com/stp/

[17]Beaumont, J. P.; et al; "Successful injection molding: process, design, and simulation". Hanser 2002.

[18] Osswald, T.A.; "Injection molding handbook". Hanser 2001.

[19] Naranjo C.,A; et al; "Injection molding processing data". Hanser 2001. 